\title{
A Study on Field Behavioral Characteristics of the Roadbed according to the Speed Increase in High-Speed Train (HEMU-430x)
}

\author{
Ki-Young Eum ${ }^{\dagger}$, Jee-Ha Lee and Young-Kon Park
}

\begin{abstract}
This paper is about the first experiment in Korea that was conducted on speeding increase up with rail speeds at $430 \mathrm{~km} / \mathrm{h}$ at high speed railway of designed $350 \mathrm{~km} / \mathrm{h}$. and analysis data collected on vibration accelerations of roadbed. There are barely references on roadbed behavior measurement with rail speeds more than $350 \mathrm{~km} / \mathrm{h}$ in Korea as it has never been conducted the experiment on it. So the experiments were confirmed the reliability through crosschecking the figures/values from respective sensors and measuring devices after measuring EMS and ICP types. Based on the study, values of vibration acceleration were less than $12 \%$ compared with the ones that conducted while speeding up of HEMU-430X. Also, figures of HSB for concrete bed tracks were 52\% against the standard. According to the results, all the performance evaluation of vibration acceleration for roadbeds in transition zones is under the standard.
\end{abstract}

Keywords : Field test, Speed up test, Vibration acceleration, HEMU-430X

\section{Introduction}

The development of domestic and international rail technology has steadily been promoted based on the speed improvement and stability. In Korea, since the era of highspeed railway was started with the opening of the Gyeongbu high-speed railway (1-phase) on April 1, 2004, the technology in the field of high-speed railway has highly been recognized around the world for the stable operation. In particular, the opening of the Gyeongbu high-speed railway line between Daegu and Busan (2-phase) on November 1, 2010 has been evaluated to serve as an opportunity to improve the quality of highs-speed railway due to the application of concrete tracks.

However, there is a relative lack of domestic research on the behavioral characteristics of track roadbed according to the speed improvement compared to this growth. In Germany and Japan, developed countries in

\footnotetext{
Corresponding author: High-Speed Railroad Infrastructure Research Team, KRRI, Uiwang 437-757, Korea

E-mail : kyeum@krri.re.kr

(c) The Korean Society for Railway 2013

http://dx.doi.org/10.7782/IJR.2013.6.2.078
}

the field of railway, a variety of measurement data and DB has steadily been accumulated by conducting measurements and experiment to determine the behavioral characteristics of tracks and roadbeds during the operation of high-speed railways. However, since Korea has no survey data to identify the behavioral characteristics of the roadbed during the operation of high-speed railway at more than $350 \mathrm{~km} / \mathrm{h}$, and acquisition of international data is also not easy, the reality is that data accumulation informatization needs to be made based on domestic proprietary technology.

In this study, data accumulation and analysis was carried out by measuring behaviors of the roadbed during train operation according to the test on the speed increase up to $430 \mathrm{~km} / \mathrm{h}$ from high-speed railway line with optimal design speed of $350 \mathrm{~km} / \mathrm{h}$. In addition, basic data that can be utilized to establish design criteria on the roadbed structures technologically available for the operation of $430 \mathrm{~km} / \mathrm{h}$-grade vehicles was accumulated. Since the roadbed of the Honam high-speed railway on which trains can operate at the speed of more than $350 \mathrm{~km} / \mathrm{h}$ is under construction in 2013, this study attempted to measure and analyze the behaviors of the roadbed due to the speed increase up to $300 \sim 421 \mathrm{~km} / \mathrm{h}$ 
Table 1. Measurement location

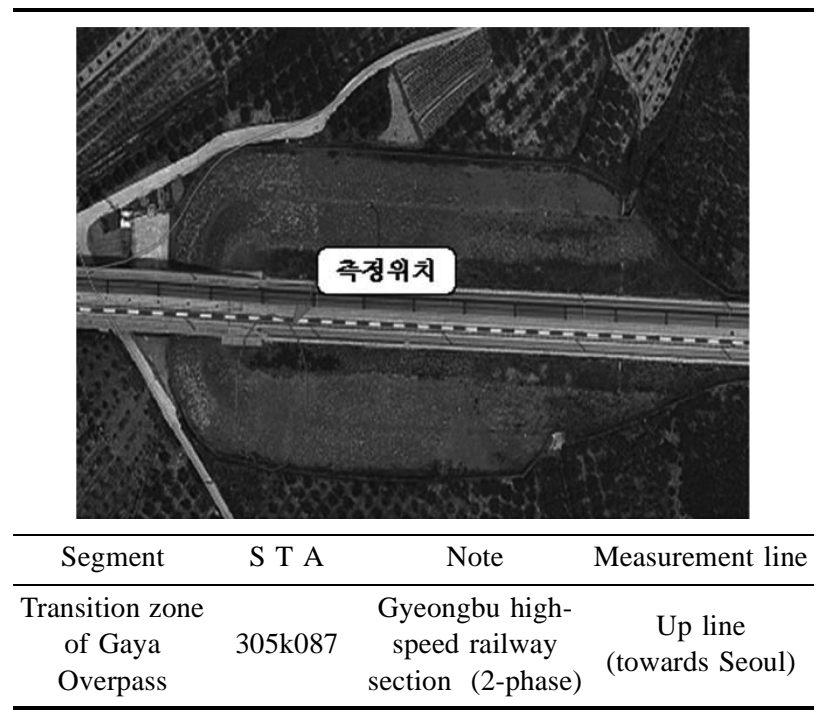

at the earthwork transition zone among phase-2 sections of the Gyeongbu high-speed railway.

\section{Field Measurement Test}

\subsection{Overview}

For field measurement location, bridge-earth transition zone of the Gaya Overpass, a plate girder bridge within the Gyeongbu high-speed railway (2-phase) sections with gross weight of $408 \mathrm{~T}$ was selected. A target vehicle was the next-generation high-speed train (HEMU-430X), and a commissioning test section was the upper main line T2 between Busan and Gomo $(120 \mathrm{~km})$ of the Gyeongbu high-speed railway line (phase-2).

Field measurement locations In the first speed increase test, an increase in speed up to $350 \mathrm{~km} / \mathrm{h}$ was completed based on the speed increase by $10 \mathrm{~km} / \mathrm{h}$ per week from July 12, 2012 to September 12, 2013, and the speed increase to the maximum speed of $421 \mathrm{~km} / \mathrm{h}$ was completed in the second speed increase test conducted from December 2, 2012 to March 31, 2013.

Table 1 shows the status of measurement location. The location of measurement target is the roadbed of transition zone in the Gaya Overpass, and target structures include abutment, HSB, approach slabs and HSB adjacent reinforced roadbed and roadbed slope area, etc. The vibration acceleration of the roadbed and concrete track according to the train loads was measured.

\subsection{Measurement items and standards}

As fill-in sensors using geotechnical drilling equipment such as earth pressure gauge, magnetic extensometer, pie-

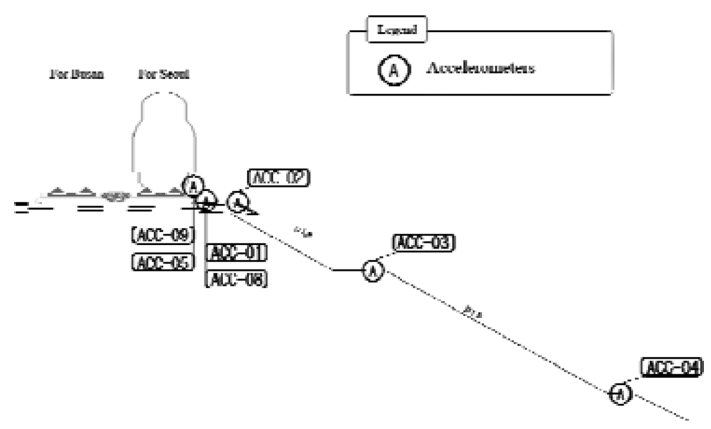

Fig. 1. Installation status of the ground vibration accelerometer

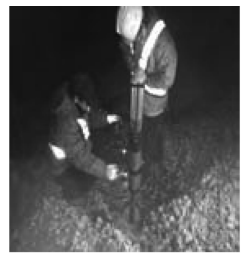

(a) Roadbed drilling

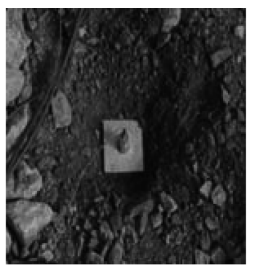

(b) Sensor installation

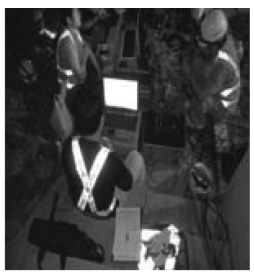

(c) Logger wiring and accelerometer measurement
Fig. 2. Installation sensors and measurement

zometer and groundwater level meter can damage to the roadbed during installation, their use was rejected by the quest of the governing body. However, since the roadbed vibration accelerometer can be installed by digging up to $10 \mathrm{~cm}$ from the surface, it was used for field measurement in this study. Fig. 1 shows the installation status of the ground vibration accelerometer.

Fig. 2 shows photos of the scene in which the vibration accelerometer ACC-01 is being installed. As shown in the figure, rubble stones on the upper surface in the side of HSB were removed, and sensors were installed in the reinforced roadbed.

Table 2 shows main specifications for measuring devices and roadbed sensors by installation location. Sensors are waterproof, and automated measurement is possible. As for measuring devices, three kinds of data loggers, including DEWETRON, CR9000X and NI cRIO-9025 were used in parallel, and duplicate measurement was made using two types of sensors such as MEMS and ICP. That's because there is no existing data carried on the roadbed behavior measurement at the train speed of more than $350 \mathrm{~km} / \mathrm{h}$ in Korea, which leads to the need to verify reliability by cross-examination on the results obtained from different sensors and measuring devices.

In selection of vibration accelerometer, the measurement $\mathrm{Hz}$ was taken into account. The ground vibration 
A Study on Field Behavioral Characteristics of the Roadbed according to the Speed Increase in High-Speed Train (HEMU-430x)

Table 2. Measuring devices and roadbed sensors

\begin{tabular}{|c|c|c|c|c|c|}
\hline Sensor name & $\begin{array}{l}\text { Measurement } \\
\text { method }\end{array}$ & $\begin{array}{l}\text { Model name } \\
\text { (Manufacturer) }\end{array}$ & Installation location & Measurement range & Measuring devices \\
\hline \multirow{3}{*}{ ACC-01 } & MEMS & $\begin{array}{c}4810 \mathrm{~B} \\
\text { (Measurement) }\end{array}$ & \multirow{3}{*}{ Reinforce roadbed in transition zone } & $\pm 5 \mathrm{~g}(0.0 \sim 250 \mathrm{~Hz})$ & \multirow{11}{*}{$\begin{array}{l}\text { Waterproof-type } \\
\text { automated and } \\
\text { compatible } \\
\text { measurement logger : } \\
\text { DEWETRON, } \\
\text { CR9000X, } \\
\text { NI cRIO-9025, etc. }\end{array}$} \\
\hline & ICP & 393B31(PCB) & & $\pm 0.5 \mathrm{~g}(0.1 \sim 200 \mathrm{~Hz})$ & \\
\hline & ICP & 393B12(PCB) & & $\pm 0.5 \mathrm{~g}(0.15 \sim 1000 \mathrm{~Hz})$ & \\
\hline ACC-02 & ICP & 393B31(PCB) & Reinforced roadbed in transition zone & $\pm 0.5 \mathrm{~g}(0.1 \sim 200 \mathrm{~Hz})$ & \\
\hline ACC-03 & ICP & 393B31(PCB) & Upper roadbed in transition zone & $\pm 0.5 \mathrm{~g}(0.1 \sim 200 \mathrm{~Hz})$ & \\
\hline ACC-04 & ICP & 393B31(PCB) & Lower roadbed in transition zone & $\pm 0.5 \mathrm{~g}(0.1 \sim 200 \mathrm{~Hz})$ & \\
\hline ACC-05 & ICP & 353B52(PCB) & Upper HSB in transition zone & $\pm 10 \mathrm{~g}(0.1 \sim 200 \mathrm{~Hz})$ & \\
\hline ACC-06 & ICP & 353B52(PCB) & Abutment structure & $\pm 10 \mathrm{~g}(0.1 \sim 200 \mathrm{~Hz})$ & \\
\hline ACC-07 & ICP & $393 \mathrm{C}(\mathrm{PCB})$ & Approach slab in transition zone & $\pm 2.5 \mathrm{~g}(0.1 \sim 200 \mathrm{~Hz})$ & \\
\hline ACC-08 & MEMS & 393B31(PCB) & $\begin{array}{l}\text { Reinforced roadbed in standard } \\
\text { banking setion }\end{array}$ & $\pm 0.5 \mathrm{~g}(0.1 \sim 200 \mathrm{~Hz})$ & \\
\hline ACC-09 & MEMS & $\begin{array}{c}4810 \mathrm{~B} \\
\text { (Measurement) }\end{array}$ & $\begin{array}{l}\text { Upper HSB in standard banking } \\
\text { section }\end{array}$ & $\pm 5 \mathrm{~g}(0 \sim 200 \mathrm{~Hz})$ & \\
\hline
\end{tabular}

Table 3. Sensor specifications

\begin{tabular}{|c|c|c|c|}
\hline Manufacturer & Sensor type & Model name & Details \\
\hline Measurement & MEMS & $4810 \mathrm{~B}$ & $\begin{array}{l}\text { - Range }(\mathrm{g}): \pm 2 \text { or } 5 \mathrm{~g} \\
\text { - Sensitivity(mV/g): } 1,000 \\
\text { - Frequency Response(Hz): 0 200 or 0 250 } \\
\text { - Natural Frequency(Hz): } 800 \\
\text { - Non-Linearity(\%FSO): } \pm 1.0\end{array}$ \\
\hline PCB & ICP & 393B31 & $\begin{array}{l}\text { - Range }(\mathrm{g}): \pm 0.5 \\
\text { - Sensitivity(mV/g): 10,000 } \\
\text { - Frequency Response(Hz): 0.1 200 } \\
\text { - Non-Linearity(\%FSO): } \pm 1 \\
\text { - Transverse Sensitivity(\%): <1 } \\
\text { - Overload Limit (Shock): } \pm 40 \mathrm{~g} \mathrm{pk}\end{array}$ \\
\hline PCB & ICP & $393 \mathrm{C}$ & $\begin{array}{l}\text { - Range }(\mathrm{g}): \pm 2.5 \\
\text { - Sensitivity(mV/g): } 1,000 \\
\text { - Frequency Response(Hz): 0.025 800 } \\
\text { - Non-Linearity(\%FSO): } \pm 1 \\
\text { - Transverse Sensitivity }(\%):<5 \\
\text { - Overload Limit (Shock): } \pm 100 \mathrm{~g} \mathrm{pk}\end{array}$ \\
\hline PCB & ICP & 353B52 & $\begin{array}{l}\text { - Range }(\mathrm{g}): \pm 10 \\
\text { - Sensitivity(mV/g): } 500 \\
\text { - Frequency Response(Hz): } 1 \sim 2,000 \\
\text { - Non-Linearity(\%FSO): } \pm 1 \\
\text { - Transverse Sensitivity }(\%):<5 \\
\text { - Overload Limit (Shock): } \pm 4,000 \mathrm{~g} \text { pk }\end{array}$ \\
\hline
\end{tabular}

regards low-frequency band of less than $100 \mathrm{~Hz}$ as the frequency of interest. Since the high-frequency band due to the vibration of trains decreases rapidly or disappears during the roadbed vibration propagation process, sensors with high-frequency range as measurement target should be excluded from the selection of measurement frequency range for vibration accelerometer. In general, the ground vibration measurement range of high-speed trains 
Table 4. Speed up test

\begin{tabular}{|c|c|c|c|c|c|}
\hline Segment & Test date & $\begin{array}{c}\text { Maximum } \\
\text { speed }\end{array}$ & Segment & Test date & $\begin{array}{c}\text { Maximum } \\
\text { speed }\end{array}$ \\
\hline \multirow{6}{*}{$\begin{array}{c}1^{\text {st }} \\
\text { speed } \\
\text { increase } \\
\text { test }\end{array}$} & '12.7.15 & $300 \mathrm{~km} / \mathrm{h}$ & \multirow{12}{*}{$\begin{array}{c}2^{\text {nd }} \\
\text { speed } \\
\text { increase } \\
\text { test }\end{array}$} & '12.12.23 & $396 \mathrm{~km} / \mathrm{h}$ \\
\hline & 12.8 .12 & $312 \mathrm{~km} / \mathrm{h}$ & & '12.12.27 & $394 \mathrm{~km} / \mathrm{h}$ \\
\hline & '12.8.16 & $321 \mathrm{~km} / \mathrm{h}$ & & '12.12.30 & $394 \mathrm{~km} / \mathrm{h}$ \\
\hline & 12.8 .23 & $334 \mathrm{~km} / \mathrm{h}$ & & '13.01.17 & $370 \mathrm{~km} / \mathrm{h}$ \\
\hline & '12.9.01 & $342 \mathrm{~km} / \mathrm{h}$ & & '13.01.20 & $396 \mathrm{~km} / \mathrm{h}$ \\
\hline & 12.9 .08 & $342 \mathrm{~km} / \mathrm{h}$ & & '13.01.27 & $400 \mathrm{~km} / \mathrm{h}$ \\
\hline \multirow{6}{*}{$\begin{array}{c}\text { 2nd } \\
\text { Speed } \\
\text { Increase } \\
\text { test }\end{array}$} & '12.11.29 & $351 \mathrm{~km} / \mathrm{h}$ & & '13.02.03 & $400 \mathrm{~km} / \mathrm{h}$ \\
\hline & '12.12.02 & $354 \mathrm{~km} / \mathrm{h}$ & & '13.02.24 & $413 \mathrm{~km} / \mathrm{h}$ \\
\hline & '12.12.09 & $355 \mathrm{~km} / \mathrm{h}$ & & '13.02.28 & $412 \mathrm{~km} / \mathrm{h}$ \\
\hline & '12.12.13 & $378 \mathrm{~km} / \mathrm{h}$ & & '13.03.03 & $400 \mathrm{~km} / \mathrm{h}$ \\
\hline & '12.12.16 & $383 \mathrm{~km} / \mathrm{h}$ & & '13.03.28 & $421 \mathrm{~km} / \mathrm{h}$ \\
\hline & '12.12.20 & $386 \mathrm{~km} / \mathrm{h}$ & & '13.03.31 & $420 \mathrm{~km} / \mathrm{h}$ \\
\hline
\end{tabular}

is up to $3 \mathrm{~m} / \mathrm{s}^{2}$ or less, and it is usually less than $1.0 \mathrm{~m} / \mathrm{s}^{2}$. However, since the value of the ground vibration can become very large in the section where impact load occurs due to the difference of stiffness, point with poor track flatness and shock caused by defects in vehicles, and case where there is a gap between concrete track and roadbed as in transition zone, the durability of sensors can be damaged by the repeated action of acceleration that exceeds the measurement range. In this regard, it is required to select sensors with sufficient measurement range. Accordingly, the accelerometer with a measurement range of \pm 5 to $\pm 10 \mathrm{~g}$ was used in structure abutment and HSB where significant thermal vibration is expected to be delivered, and that of $\pm 2.5 \mathrm{~g}$ was used for approach slabs of the abutment transition zone. In addition, the accelerometer with a range of $\pm 0.5 \mathrm{~g}$ was used in the reinforced roadbed, upper roadbed and lower roadbed in which train vibrations are indirectly delivered to the ground.

\subsection{Test conditions}

As shown in Table 4, the speed increase of the nextgeneration high-speed train was proceeded by $10 \mathrm{~km} / \mathrm{h}$ from $300 \mathrm{~km} / \mathrm{h}$ at one to two week intervals, starting from July 15, 2012. Train operation was made three times with the same planned rate at about 1 hour and 20 minute intervals from the midnight. After train maintenance, the second speed increase test was conducted by increasing the speed by $10 \mathrm{~km} / \mathrm{h}$ at one to two intervals from $350 \mathrm{~km} / \mathrm{h}$ at the end of November 2012, and the speed increase was completed with maximum speed of $421 \mathrm{~km} /$ $\mathrm{h}$ on March 28. The ground vibration acceleration during

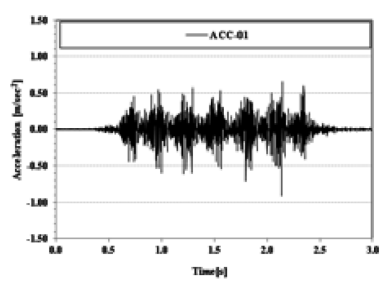

(a) Time Series of ACC-01

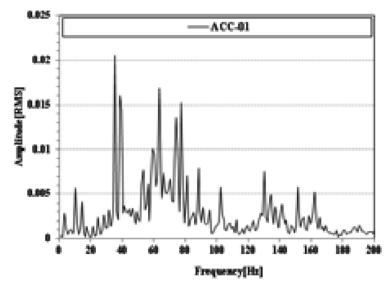

(b) FFT of ACC-01
Fig. 3 ground acceleration at $300 \mathrm{~km} / \mathrm{h}$

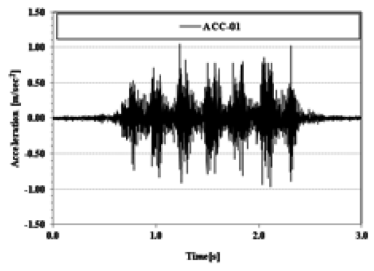

(a) Time Series of ACC-01

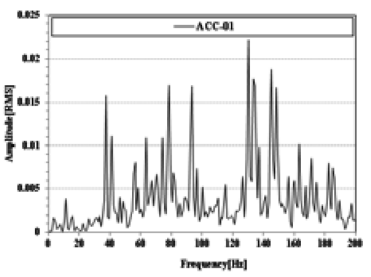

(b) FFT of ACC-01
Fig. 4 ground acceleration at $330 \mathrm{~km} / \mathrm{h}$

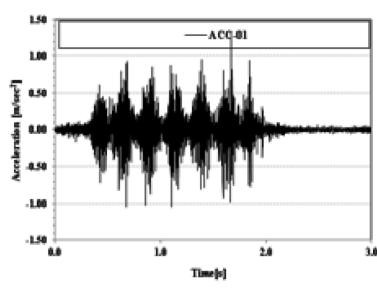

(a) Time Series of ACC-01

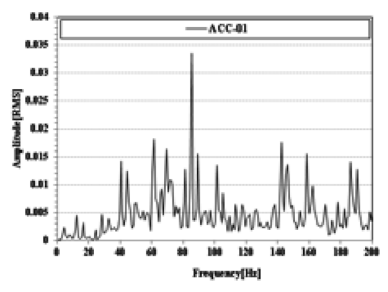

(b) FFT of ACC-01
Fig. 5 ground acceleration at $355 \mathrm{~km} / \mathrm{h}$

train operation with speed of more than $350 \mathrm{~km} / \mathrm{h}$ was measured by applying know-how technology in the second speed increase test after improving measurement methods and analyzing measurement data during the period of train operation.

\section{Analysis of Test Results}

The sampling rate was determined to be $2.5 \mathrm{kHz}$ so that response distortion and data loss can be prevented in vibration acceleration measurement. In addition, an analysis was conducted with the frequency of interest as target by processing noise components except for the ground acceleration with low-pass filtering and hi-pass filtering methods using digital filters through frequency analysis. The frequency range of interest on the ground vibration is typically less than $100 \mathrm{~Hz}$. In the case of the ground vibration accelerometer with small measurement range, as the error rate in the frequency measurement range is less than 


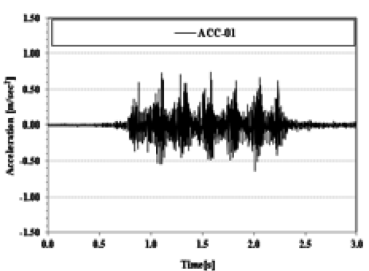

(a) Time Series of ACC-01

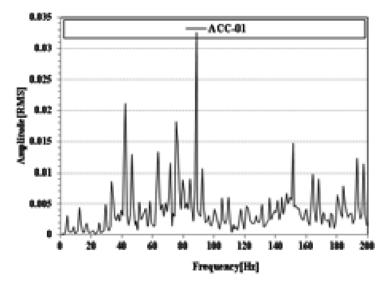

(b) FFT of ACC-01

Fig. 6 ground acceleration at $370 \mathrm{~km} / \mathrm{h}$

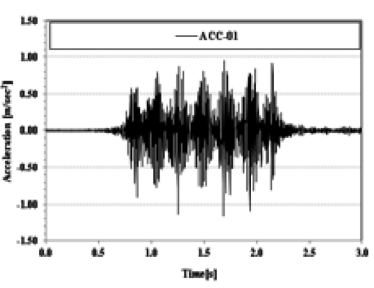

(a) Time Series of ACC-01

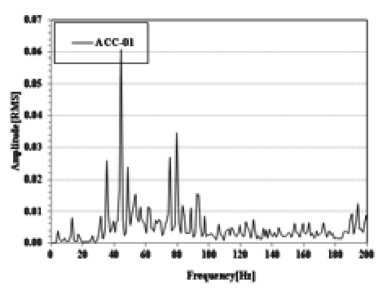

(b) FFT of ACC-01

Fig. 7 ground acceleration at $394 \mathrm{~km} / \mathrm{h}$

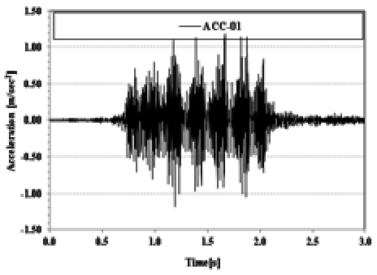

(a) Time Series of ACC-01

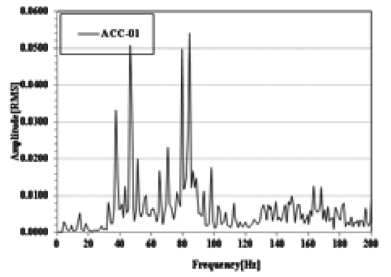

(b) FFT of ACC-01

Fig. 8 ground acceleration at $400 \mathrm{~km} / \mathrm{h}$

$1.5 \%$ at less than $200 \mathrm{~Hz}$, and the accuracy in value of frequency which is outside the range decreases, filters were set to have a low pass at about $300 \mathrm{~Hz}$ in the analysis phase.

The representative ground vibration acceleration measurement values by speed of next-generation high speed train (HEMU-430X) were schematized in Figs. 3 10. The ground vibration was measured by increasing the speed of the train by $10 \mathrm{~km} / \mathrm{h}$ from $300 \mathrm{~km} / \mathrm{h}$ to $421 \mathrm{~km} / \mathrm{h}$. In case of the speed increase, the maximum vibration acceleration of the roadbed increased from $0.8 \mathrm{~m} / \mathrm{s}^{2}$ to $1.4 \mathrm{~m} / \mathrm{s}^{2}$, and the maximum RMS of the vibration acceleration was evaluated to be $0.74 \mathrm{~m} / \mathrm{s}^{2}$. In FFT analysis results, the frequency band ranging from $18 \sim 20 \mathrm{~Hz}$ to $55 \sim 65 \mathrm{~Hz}$ was continuously detected during the train operation at the speed of $310 \sim 421 \mathrm{~km} / \mathrm{h}$. Since the battery (UPS) was used in measurement, the effect of $60 \mathrm{~Hz}$ power-supply nose is expected to be insignificant.

As shown in Figs. 5 10, the power-supply noise was removed and ICP accelerometer was additionally installed

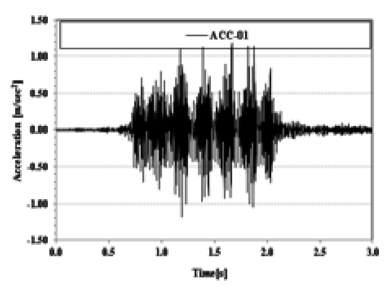

(a) Time Series of ACC-01



(b) FFT of ACC-01
Fig. 9 ground acceleration at $412 \mathrm{~km} / \mathrm{h}$

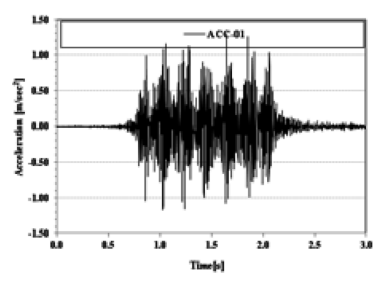

(a) Time Series of ACC-01

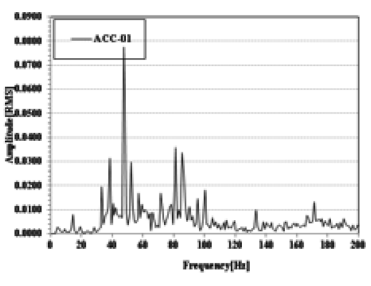

(b) FFT of ACC-01
Fig. 10 ground acceleration at $421 \mathrm{~km} / \mathrm{h}$

in case of the train speed of more than $350 \mathrm{~km} / \mathrm{h}$, so that the ground vibration caused by train axle loads and low vibration with less than $10 \mathrm{~Hz}$ could be detected well. However, since there are cases where the train axle-load ground vibration is not measured at the train speed of more than $320 \mathrm{~km} / \mathrm{h}$ as in Fig. 4, the measurement was made by increasing the sample from the current $1 \mathrm{kHz}$ to $2.5 \mathrm{kHz}$, and an accelerometer jig was installed to enhance the vibration sensitivity of the low-frequency band from $360 \mathrm{~km} / \mathrm{h}$.

Fig. 11 shows that as the train speed increased from $300 \mathrm{~km} / \mathrm{h}$ to $421 \mathrm{~km} / \mathrm{h}$, the roadbed vibration acceleration also increased. As shown in Fig. 11(a), the maximum vibration acceleration of the roadbed was measured at $2.0 \mathrm{~m} / \mathrm{s}^{2}$ during the operation of HEMU train, and the maximum RMS value at $0.6 \mathrm{~m} / \mathrm{s}^{2}$. In consideration that the standard of the roadbed vibration acceleration is $5.0 \mathrm{~m} / \mathrm{s}^{2}$, the above figures were found to meet the standards, showing $40 \%$, compared to the maximum value and $12 \%$ compared to RMS. In addition to ACC-01, ACC-02, ACC-03, and ACC-04 also satisfied the vibration standards.

Fig. 12 shows schematic diagram that displays measurement values of the roadbed vibration acceleration compared to standard values during speed increase test of HEMU-430X. As shown in Table 5, the vibration acceleration was measured at less than $12 \%$ in the roadbed, but it was $52 \%$ compared to the standard value in HSB of the concrete track. Accordingly, the results of performance evaluation on the vibration acceleration of the roadbed in 
Ki-Young Eum, Jee-Ha Lee, and Young-Kon Park / IJR, 6(2), 78-84, 2013

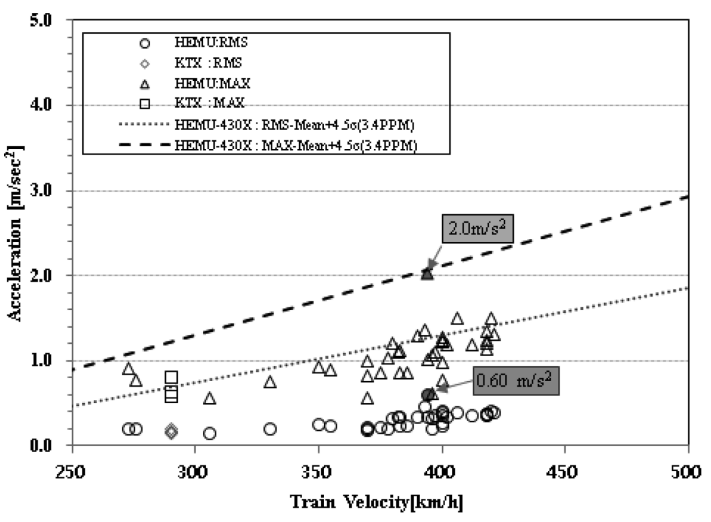

(a) Time Series of ACC-01

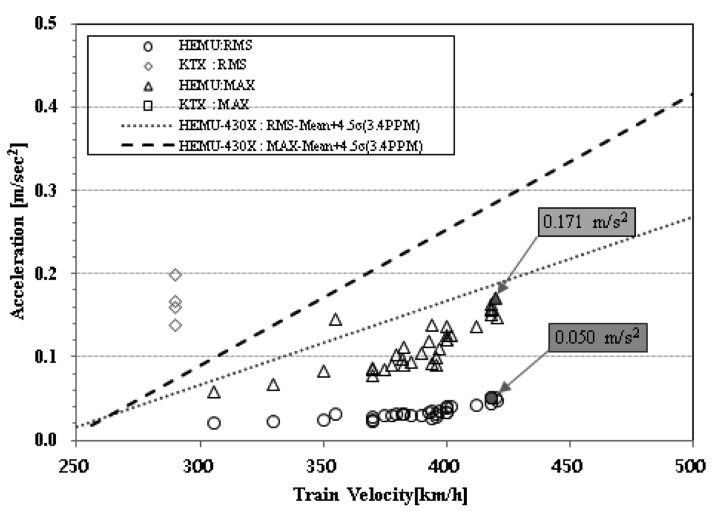

(c) Time Series of ACC-03

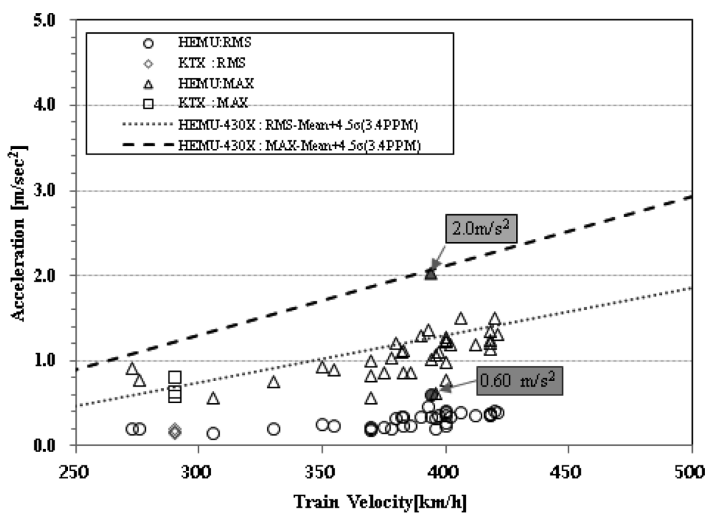

(b) Time Series of ACC-02

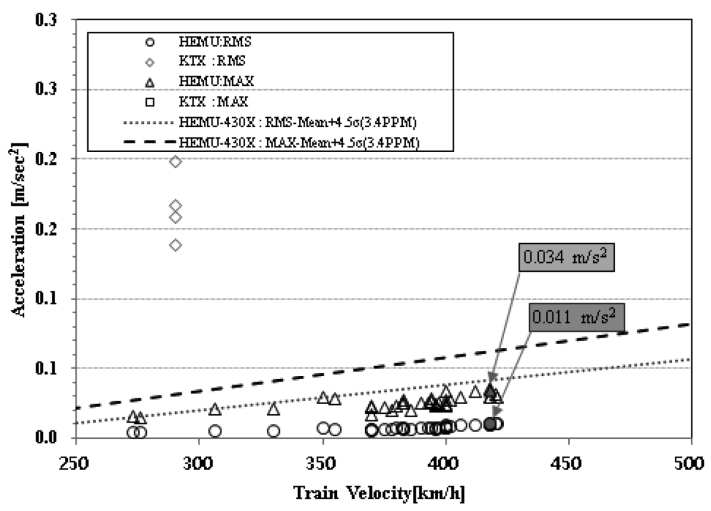

(d) Time Series of ACC-04

Fig. 11 Results of ground acceleration by speed

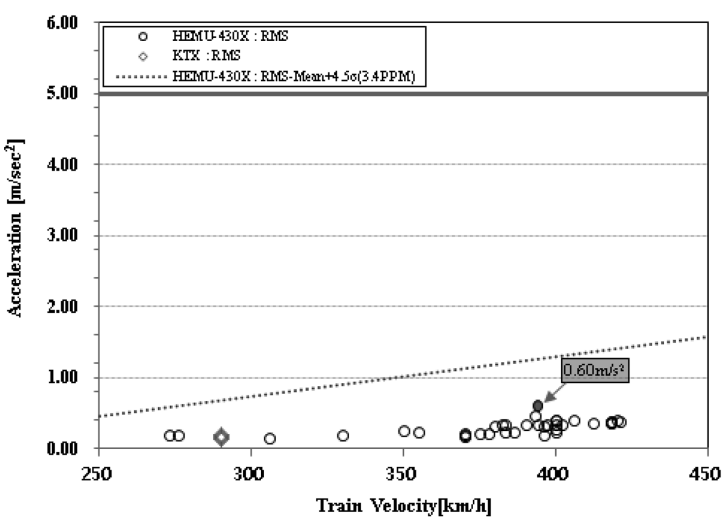

(a) Reinforced roadbed (ACC-01)

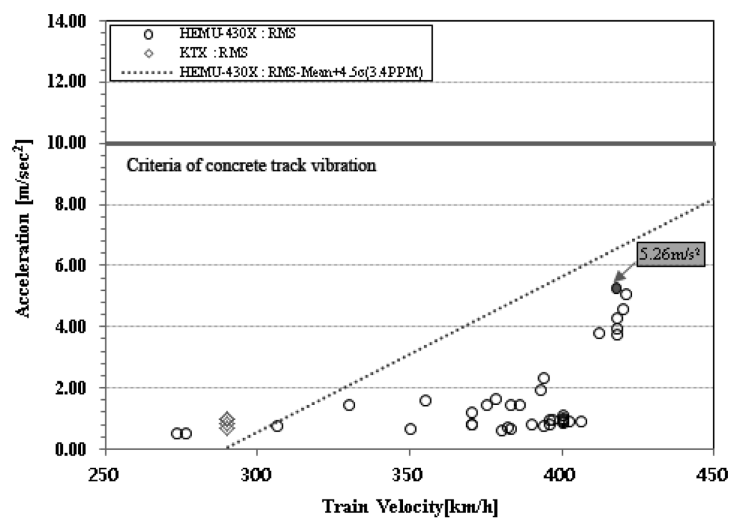

(b) HSB(ACC-05)

Fig. 12 Safety standard of ground acceleration

Table 5 Results of measeurements

\begin{tabular}{cccccc}
\hline Measurement items & Segment & Standard values & $\begin{array}{c}\text { Maximum measurement values } \\
\text { (Speed) }\end{array}$ & Performance evaluation & Remarks \\
\hline \multirow{2}{*}{$\begin{array}{c}\text { Vibration } \\
\text { acceleration }\end{array}$} & Roadbed & $5 \mathrm{~m} / \mathrm{s}^{2}$ & $0.6 \mathrm{~m} / \mathrm{s}^{2}(394 \mathrm{~km} / \mathrm{h})$ & Within standards(12\%) & LPF 300Hz RMS \\
\cline { 2 - 6 } & HSB & $10 \mathrm{~m} / \mathrm{s}^{2}$ & $5.26 \mathrm{~m} / \mathrm{s}^{2}(418 \mathrm{~km} / \mathrm{h})$ & Within standards $(52 \%)$ & LPF 300Hz RMS \\
\hline
\end{tabular}


A Study on Field Behavioral Characteristics of the Roadbed according to the Speed Increase in High-Speed Train (HEMU-430x)

transition zone of Gaya Overpass with HEMU-430X as target were all evaluated to be behaviors within the range of standard values.

\section{Conclusion}

In this study, the vibration acceleration was measured in real time through the test of speed increase from 300 to $421 \mathrm{~km} / \mathrm{h}$ on the high-speed train (HEMU-430x), which was conducted in the Gyeongbu high-speed railway sections (2-phase), and the behavioral characteristics of the roadbed due to the increase in train speed were analyzed experimentally. The analysis results showed that the maximum vibration acceleration was measured at less than $12 \%$, which was within the standard of the vibration acceleration $\left(5 \mathrm{~m} / \mathrm{s}^{2}\right)$, showing the amount of increase from
$0.6 \mathrm{~m} / \mathrm{s}^{2}$ to $1.4 \mathrm{~m} / \mathrm{s}^{2}$ as speed increased, and it was measured at $52 \%$ compared to standard values in HSB of concrete track. The maximum RMS value was evaluated to be $0.74 \mathrm{~m} / \mathrm{s}^{2}$, and through FTF analysis, frequency bands ranging from $18 \sim 20 \mathrm{~Hz}$ to $55 \sim 65 \mathrm{~Hz}$ were consistently detected during the train operation at the speed of 310 to $421 \mathrm{~km} / \mathrm{h}$.

\section{References}

1. Korea Rail Network Authority (2010). "Services of testing Verification of facility from Daegu to Busan in Gyoungbu high speed railraod."

2. Japan Railway Track Consultants (2009). "Performance criteria and case studies of orbit system in Japan." 